\title{
INFECTIOUS DISEASES, NSW: MAY 1998
}

\section{TRENDS}

Notifications of infectious diseases have continued to follow expected seasonal trends through to April 1998, with the exception of arboviral infections with fewer notifications than usual (Figure 1).

With the influenza season close at hand, in this edition we present the first data from the NSW influenza surveillance program, and review our current approach to immunisation in the workplace. In addition, with some overseas reports indicating recent declines in AIDS cases in some western countries, we review HIV and AIDS notifications in NSW.

\section{INFLUENZA VACCINATION CAMPAIGN}

A campaign to remind those at risk from the complications of influenza to have themselves vaccinated was launched by the Health Minister on 18 May. The campaign was mounted by the Pharmacy Guild of Australia, with the support of the NSW Health Department, as part of National Pharmacy Week, and took the form of a series of radio advertisements combined with a public relations campaign. The main message of the campaign, which was aimed particularly at the elderly, was that it is still not too late to be immunised. Although influenza immunisation rates have increased in New South Wales in recent years, about half of those for whom vaccination is recommended remain unimmunised.

\section{NSW INFLUENZA SURVEILLANCE}

Although a widespread epidemic did not develop following the outbreak of influenza in Hong Kong at the end of 1997, the emergence of the H5N1 subtype and its potential to re-emerge and cause pandemic disease have concentrated attention worldwide on influenza surveillance. The 'Sydney' strain of the H3N2 subtype of influenza A, which was responsible for considerable 'flu activity in parts of Australia in 1997, has since been responsible for a widespread epidemic in the United States in the northern hemishere winter and has also been active in Europe and Asia. In the light of these outbreaks and the imminent influenza season in Australia, it was timely to review surveillance measures in New South Wales. Proposals developed to strengthen surveillance are now being implemented. One essential element of improved surveillance was recognised to be timely feedback of information about influenza activity to those involved in influenza surveillance and others who wished to know. A weekly report has been developed (NSW Influenza Surveillance Activity Update) and the contents of the first three reports are summarised below. The weekly reports are prepared by the AIDS/Infectious Diseases Branch of the NSW Health Department, in collaboration with the South East Area Laboratory Service, the Institute of
Readers will notice a change in our regular infectious diseases graphs. Instead of showing disease reports for the previous 12 months with historical comparisons, we'll now show you disease reports over the entire previous four years or so.

Clinical Pathology and Medical Research, the New Children's Hospital, the South West Area Pathology Service, Royal Prince Alfred Hospital, Pacific Laboratory Medical Services, participating general practitioners and the Hunter, New England, Northern Sydney and Southern Public Health Units.

Activity update (Weekly reports nos. 1-3, 26 April to 16 May 1998)

Summary: Both clinical and virological indices of activity were low over this period.

Clinical activity: Reports of consultations for influenzalike-illness from the NSW Sentinel General Practitioner Surveillance Scheme were received from three Public Health Units (PHUs). Weekly rates ranged from 5 to 11 per 1000 consultations (Figure 2), similar to the rates seen in previous years.

Virological activity: Reports of diagnoses on influenza infection were received from four laboratories in New South Wales. Only one report of an isolate of influenza virus was received: an influenza A subtype $\mathrm{H} 3 \mathrm{~N} 2$ virus from a person who had recently returned from the Middle East (strain typing results on this virus are awaited). Two diagnoses of influenza A infection were confirmed by direct immunofluorescent detection of antigen and one other by a fourfold rise in antibodies. No influenza B infections were confirmed.

A total of 106 respiratory syncytial virus infections were reported over the same period: respiratory syncytial virus activity usually rises at this time of year, with the majority of infections being confirmed in the under-one-year age group. Very few other respiratory virus infections were confirmed during this period.

\section{Directed virological surveillance}

The NSW Health Department has proposed a surveillance initiative which will involve 10 to 20 sentinel general practitioners submitting up to five specimens per week each for virological analysis. The potential advantages of such schemes are that influenza isolates are generally obtained earlier in the season than by routine laboratory surveillance, the results are more representative of the 


\section{FIGURE 1}

REPORTS OF SELECTED INFECTIOUS DISEASES, NSW, JANUARY 1994 TO APRIL 1998, BY MONTH OF ONSET

These are preliminary data: case counts in recent months may increase because of reporting delays
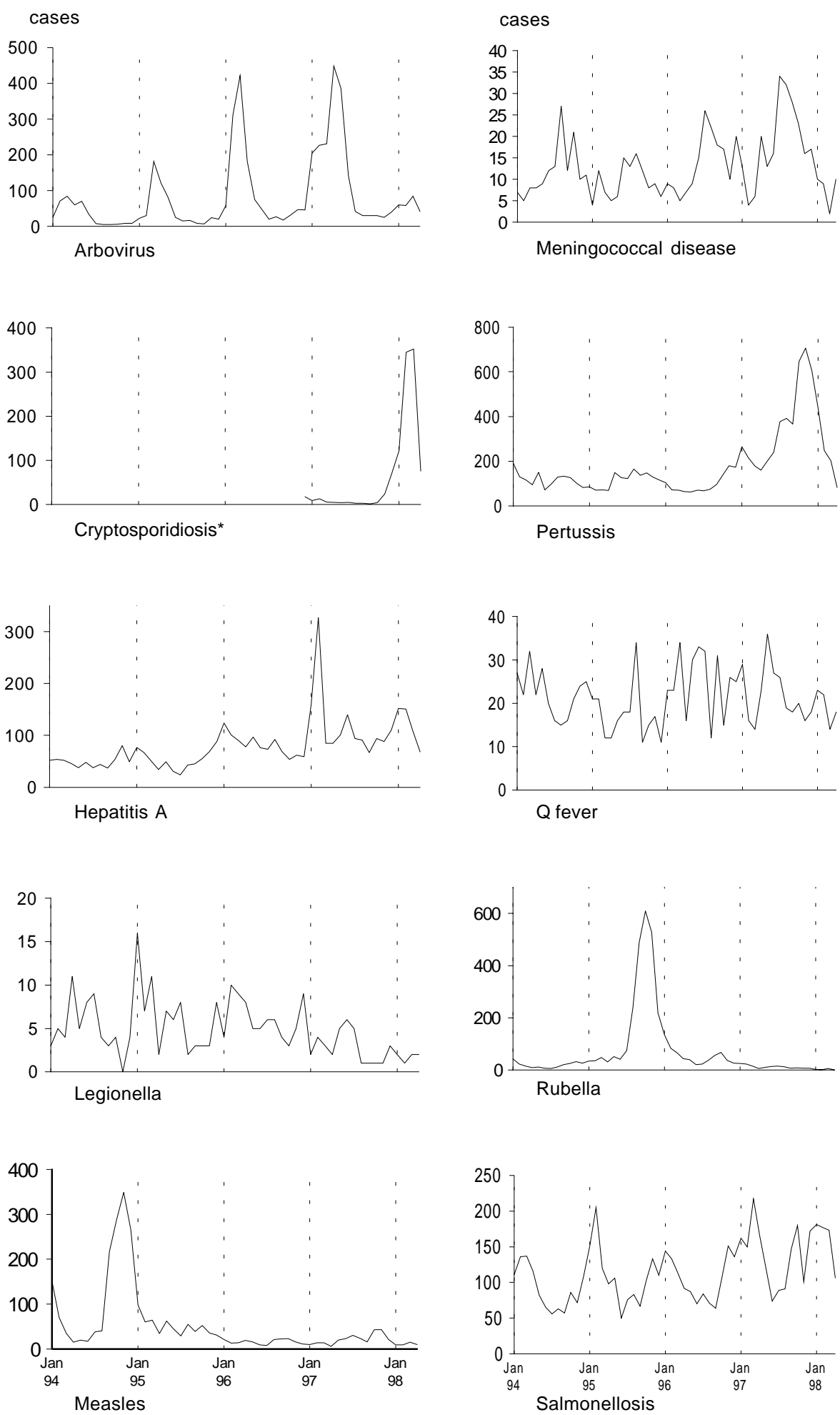

* not reportable before December 1996 
viruses circulating in the community (than the viruses causing illness in hospitalised patients), specimens are obtained from a more representative age spectrum than can be achieved from hospital-based surveillance, the results are obtained by the consistent use of standardised sampling methods and the results are available rapidly. The recruitment of general practitioners continues and reporting will begin later in the season.

\section{IMMUNISATION AGAINST INFLUENZA IN THE WORKPLACE}

\section{John Watson}

Medical Epidemiologist, AIDS/Infectious Diseases Branch There is considerable uncertainty about the appropriateness of influenza immunisation of fit adults of working age in the occupational setting. The National Health and Medical Research Council (NHMRC) states that 'mass vaccination of individuals in particular industries or worksites cannot usually be justified on public health grounds', ${ }^{1}$ but does leave the way open for supporting the immunisation of occupational groups in certain circumstances.

The problem is not one of protective efficacy (influenza vaccine provides a good level of protection in most years, especially in working-age adults and children) but with cost-effectiveness and uptake. From a population perspective, it makes a lot of sense to recommend immunisation of those people who are at increased risk of the complications of influenza, not only to prevent serious morbidity and mortality but also to reduce health care (especially hospital) expenditure on treatment.

For younger people, the benefits, both health and financial, are less clear cut: for most of this group influenza is a self-limiting illness, albeit a miserable one, and they soon return to work. In addition, influenza is very variable in its extent and severity from year to year, and major epidemics occur only every few years. Nevertheless, in the United States, physicians are recommended to immunise any person who wishes to reduce the likelihood of becoming ill with influenza. ${ }^{2}$

From an employer's point of view, the calculations may be different. An employer may be prepared to pay a premium to reduce absenteeism during influenza epidemics. This may be especially important for businesses or organisations involved in work where loss of more than a small proportion of the workforce at one time is more critical than the overall annual level of absenteeism, for example, companies involved in continuous industrial processes. Health services, too, have a special interest in not losing employees on sick leave during influenza epidemics, because this is the very time that workloads are increased. Both the NHMRC and the United States Centers for Disease Control (CDC) recommend immunisation of groups that can transmit influenza to

\section{FIGURE 2}

REPORTS OF INFLUENZA-LIKE ILLNESS FROM NSW SENTINEL GENERAL PRACTICES, APRIL-MAY 1998, BY WEEK OF CONSULTATION, WITH HISTORICAL COMPARISONS

cases 
persons at high risk, and the CDC guidance goes on to recommend vaccination of "persons who provide essential community services ... to minimize disruption of essential activities during influenza outbreaks'. ${ }^{1,2}$

One of the main problems in the occupational setting has been obtaining adequate levels of vaccination uptake. Among health care workers in particular, uptake has been generally poor. Employers may have to invest a lot of resources to obtain a high enough uptake level to produce any appreciable reduction in sickness absence. In addition, they may have to invest these resources for three or four years before they prevent the substantial absence associated with a major epidemic.Assessing costeffectiveness in this area is very difficult. Studies need to be large, blinded and controlled. Few have been good. An exception is the study by Nichol et al. published in 1995, which showed cost savings in a working-age population as a result of the use of influenza immunisation. ${ }^{3}$

Advice to employers should probably include an appreciation of these issues, as the ultimate decision will be that of the employer, who will pay for a workplacebased immunisation campaign. While mounting scientifically robust investigations of the cost-effectiveness of this intervention in different Australian settings will be difficult because of the large studies required, much could be learnt from the description of workplace campaigns that are carried out, including costs, methods employed, levels of uptake and difficulties encountered.

\section{REFERENCES}

1. National Health and Medical Research Council Communicable Diseases Standing Committee. The Australian immunisation handbook. 6th edn. Canberra: Australian Government Publishing Service, 1997.

2. Centers for Disease Control and Prevention. Prevention and control of influenza: recommendations of the advisory committee on immunisation practices(ACIP). MMWR 1988; 47 (RR-6): 1-26.

3. Nichol KL, Margolis KL, Lind A, et al. The effectiveness of vaccination against influenza in healthy working age adults. N Engl J Med 1995; 333: 889-893.

\section{TOO EARLY TO CELEBRATE?}

Recent evidence from the United States shows declines of close to 75 per cent in both AIDS-related mortality and morbidity over the two to three years to 1997 . These remarkable gains have been attributed largely to more intensive use of combined antiviral therapies. ${ }^{1}$ In addition, the period of AIDS-free survival in persons living with HIV appears to be increasing. ${ }^{2}$

In New South Wales, surveillance of AIDS has been used to track the epidemic since the mid-1980s. Concern that AIDS surveillance was insufficient for tracking trends in HIV infections (because of the delay between initial infection and onset of AIDS-defining illnesses) led to an upgrading of laboratory-based HIV surveillance in 1991.

Recent trends in NSW AIDS surveillance data from 1991 to 1997 show some cause for optimism, with reports of AIDS diagnoses declining from a peak of 552 in 1995, to 293 in 1997 (Figure 3). This represents a 47 per cent decline in cases over two years. These data suggest that the increased use of combined antiviral therapy to treat HIV infections may have had a similar success in NSW as it has in the United States, although further analyses are required to support this hypothesis.

Of concern, however, is the only modest decline in new HIV diagnoses since 1994, with 437 diagnoses in 1995 and 399 in 1997 (Figure 4). A potential negative outcome of the good news about the declining incidence of AIDS is that complacency could emerge among persons at risk of infection, who may also be tiring of public health advice about safe sex.

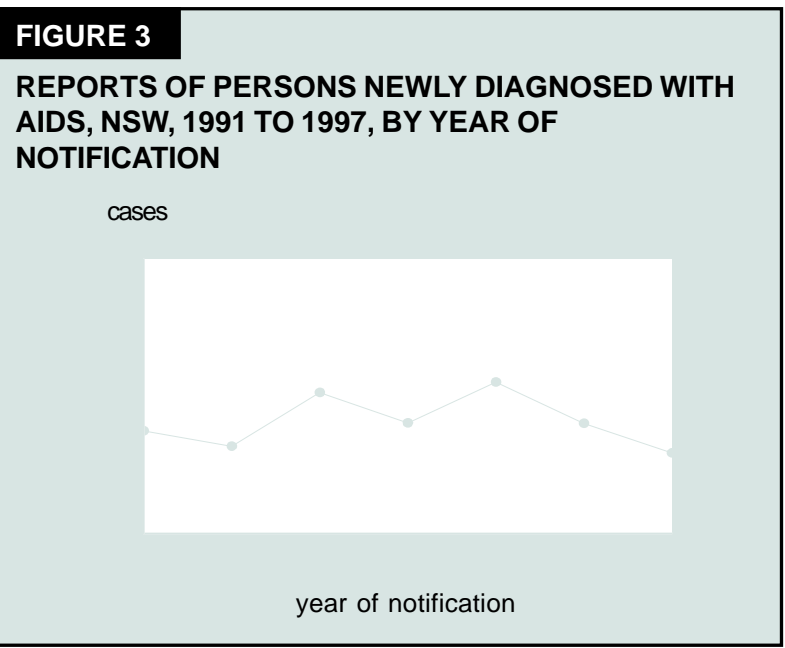

FIGURE 4

REPORTS OF PERSONS NEWLY DIAGNOSED WITH HIV, NSW, 1991 TO 1997, BY YEAR OF NOTIFICATION

year of notification 


\section{TABLE 1}

\section{REPORTS OF PERSONS WITH NEW HIV OR AIDS DIAGNOSES, NSW, 1994 AND 1997, BY REPORTED RISK EXPOSURE}

\begin{tabular}{|c|c|c|c|c|c|c|c|c|c|c|}
\hline \multirow{2}{*}{$\begin{array}{l}\text { Risk exposure } \\
\text { type }\end{array}$} & \multirow[b]{2}{*}{1995} & \multicolumn{4}{|c|}{ New HIV diagnoses } & \multicolumn{5}{|c|}{ New AIDS diagnoses } \\
\hline & & $\%^{a}$ & 1997 & $\%^{a}$ & \%change & 1995 & $\%^{a}$ & 1997 & $\%^{a}$ & \%change \\
\hline $\mathrm{MSM}^{\mathrm{b}}$ & 297 & 74 & 215 & 72 & -28 & 464 & 87 & 214 & 81 & -54 \\
\hline MSM and IDUc & 12 & 3 & 8 & 3 & -33 & 15 & 3 & 8 & 3 & -47 \\
\hline IDU & 17 & 4 & 9 & 3 & -47 & 12 & 2 & 15 & 6 & +25 \\
\hline Heterosexual & 61 & 15 & 61 & 20 & 0 & 30 & 6 & 21 & 8 & -30 \\
\hline Other & 17 & 4 & 7 & 2 & -60 & 15 & 3 & 5 & 2 & -67 \\
\hline Not stated & 33 & - & 102 & - & +209 & 16 & - & 30 & - & +88 \\
\hline Total & 437 & & 399 & & -9 & 563 & & 293 & & -47 \\
\hline
\end{tabular}

(a) $\mathrm{MSM}=$ men who have sex with men

(b) IDU = injecting drug users

(c) \% of known exposures to risk

Complacency has no place in the fight against AIDS. Evidence of just how long new HIV therapies and prophylactic regimes can stave off the onset of opportunistic infection is not yet available. The small decline in new HIV diagnoses, coupled with reports of an increase in both unprotected sex (Crawford J, Kippax S. Periodic survey: results for fourth survey, unpublished), and (perhaps as a consequence) gonorrhoea incidence, among young inner-city $\mathrm{men}^{4}$ highlights the need to remain vigilant in monitoring HIV infections and adapting prevention strategies as required.

Between 1995 and 1997, there was a large increase in the number of persons newly diagnosed with HIV infection for whom risk factors were not reported and, in contrast to other exposure groups, no decline in persons reporting heterosexual exposure to the virus. In addition, the decline in new AIDS diagnoses was least among persons reporting heterosexual contact and there was an increase in persons reporting injecting drug use (Table 1). These differences involve only relatively small numbers, but suggest that persons who acquire HIV infection through injecting drug use or heterosexual contact may be somewhat more difficult to reach with interventions.

The recent changes in AIDS-free survival time has highlighted the importance of HIV surveillance in tracking the evolution of the epidemic. ${ }^{3}$ However, the large and growing proportion of HIV notifications that are provided without risk information severely limits our ability to do this. To inform the most effective prevention strategies, doctors are urged to be vigilant in notifying new infections through the existing laboratory-based notification system, by completing and returning the laboratory-generated risk forms on persons newly diagnosed with HIV.
The NSW Health Department has been active in implementing harm-minimisation strategies, such as education and needle and syringe exchange programs, that have resulted in very low levels of HIV infection among injecting drug users. Partnerships between affected communities and government have kept HIV infections among men who have sex with men under control. However, reported increases in risk behaviours among men who have sex with men, a possible increase in HIV infections among heterosexuals, and overseas experience of increases in HIV infections among injecting drug users are reminders of the need for vigilance. Should these changes be accompanied by a failure to sustain treatment effectiveness, we could see an increase in HIV infection with a far more potent and difficult-to-manage virus. The NSW Health Department is currently developing new treatment and prevention strategies that take into account both the changing epidemiology of HIV disease and new treatments, and is liaising with laboratories to improve the completeness of HIV infection notifications.

\section{REFERENCES}

1. Palella FJ, Delaney KM, Moorman AC, et al. Declining morbidity and mortality among patients with advanced human immunodeficiency virus infection. $N$ Engl J Med 1998; 338: 853-860.

2. Hogg RS, Heath KV, Yip B, et al. Improved survival among HIV-infected individuals following initiation of antiviral therapy. JAMA 1998; 279: 450-454.

3. CDC Diagnosis and reporting of HIV and AIDS in states with integrated HIV and AIDS surveillance-United States, January 1994-June 1997. MMWR 1998; 47: 309-314.

4. Infectious diseases: Gonorrhoea increases. NSW Public Health Bulletin, March 1998. Sydney: NSW Health Department, 1998: 41. 
TABLE 2

INFECTIOUS DISEASE NOTIFICATIONS RECEIVED IN APRIL 1998 BY AREA HEALTH SERVICES

\begin{tabular}{|c|c|c|c|c|c|c|c|c|c|c|c|c|c|c|c|c|c|c|c|}
\hline \multirow[b]{2}{*}{ Condition } & \multicolumn{17}{|c|}{ Area Health Service (1998) } & \multicolumn{2}{|c|}{ Total } \\
\hline & CSA & NSA & WSA & WEN & sws & CCA & HUN & ILL & SES & NRA & MNC & NEA & MAC & MWA & FWA & GMA & SA & for $\mathrm{Apr}^{\star \star}$ & To date ${ }^{\star \star}$ \\
\hline \multicolumn{20}{|l|}{ Blood-borne and sexually transmitted } \\
\hline AIDS & - & - & 2 & 1 & - & 1 & - & 1 & 1 & - & - & - & - & - & - & - & - & 6 & 34 \\
\hline HIV infection* & - & - & - & - & - & - & - & - & - & - & - & - & - & - & - & - & - & - & 114 \\
\hline \multirow{2}{*}{$\begin{array}{l}\text { Hepatitis B: acute viral* } \\
\text { Hepatitis B: other* }\end{array}$} & - & - & 2 & - & - & - & - & - & - & - & - & - & - & - & - & - & - & 2 & 19 \\
\hline & 29 & 18 & 11 & 5 & - & 1 & 1 & 8 & 20 & - & 1 & 2 & - & 4 & - & - & 1 & 101 & 1041 \\
\hline Hepatitis C: acute viral ${ }^{*}$ & - & - & 1 & - & - & - & - & - & - & - & - & - & - & - & - & - & - & 1 & 14 \\
\hline \multirow{2}{*}{$\begin{array}{l}\text { Hepatitis C: other } \\
\text { Hepatitis D: unspecified* }\end{array}$} & 42 & 23 & 58 & 39 & 2 & 35 & 37 & 15 & 53 & 20 & 24 & 10 & 3 & 18 & - & 8 & 23 & 410 & 2773 \\
\hline & - & - & - & - & - & - & - & - & - & - & - & - & - & - & - & - & - & - & 1 \\
\hline Hepatitis: acute viral (not otherwise specified) & - & - & - & - & - & - & - & - & - & - & - & - & - & - & - & - & - & - & 2 \\
\hline Gonorrhoea* ${ }^{*}$ & 7 & 5 & - & - & - & 1 & 2 & 1 & 30 & - & 3 & 1 & - & - & - & 1 & - & 51 & 294 \\
\hline Syphilis & 7 & 5 & - & - & - & 1 & - & - & 5 & 4 & - & - & 1 & 5 & - & - & - & 28 & 158 \\
\hline \multirow{2}{*}{$\begin{array}{l}\text { Vector-borne } \\
\text { Arboviral infection* }\end{array}$} & & & & & & & & & & & & & & & & & & & \\
\hline & 1 & - & - & - & - & - & 4 & - & - & 12 & 14 & 4 & 1 & 2 & 2 & 1 & - & 41 & 248 \\
\hline Malaria* & - & - & - & 1 & - & - & 2 & 1 & 3 & - & - & - & 1 & 1 & - & - & - & 9 & 56 \\
\hline Zoonoses & - & & & & & & & & & & & & & & & & & & \\
\hline Brucellosis* & - & - & - & - & - & - & - & - & - & - & - & - & - & - & - & - & - & - & - \\
\hline Leptospirosis* & - & - & - & - & - & - & - & - & - & - & 1 & - & - & - & - & - & - & 1 & 9 \\
\hline Q fever ${ }^{*}$ & - & - & - & - & - & - & 2 & - & - & 1 & 1 & 3 & 9 & 1 & 1 & - & - & 18 & 81 \\
\hline Respiratory and other & & & & & & & & & & & & & & & & & & & \\
\hline Blood lead level & 4 & 2 & 1 & 2 & - & 3 & 19 & - & 2 & 3 & 1 & - & - & 2 & - & - & - & 39 & 270 \\
\hline Legionnaires' disease & 1 & - & 1 & - & - & - & - & - & - & - & - & - & - & - & - & - & - & 2 & 7 \\
\hline Leprosy & - & - & - & - & - & - & - & - & - & - & - & - & - & - & - & - & - & - & - \\
\hline Meningococcal (invasive) infection & - & 3 & 2 & 2 & - & 1 & - & - & 1 & 1 & - & 1 & - & - & - & - & - & 11 & 32 \\
\hline Mycobacterial tuberculosis & - & 2 & 1 & - & - & - & - & - & - & - & 1 & - & - & - & - & - & - & 4 & 79 \\
\hline Mycobacteria other than TB & 2 & 2 & - & - & - & 1 & - & - & - & - & - & - & - & - & - & - & - & 5 & 67 \\
\hline Vaccine-preventable & & & & & & & & & & & & & & & & & & & \\
\hline Adverse event after immunisation & - & - & 1 & - & - & - & - & - & 2 & 1 & 2 & - & - & - & - & 1 & - & 7 & 72 \\
\hline H. influenzae b (invasive) infection & - & - & - & - & - & - & - & - & - & - & - & - & - & - & - & - & - & - & 2 \\
\hline Measles & - & 1 & - & 1 & - & 3 & 2 & 1 & 1 & - & 4 & - & - & - & - & - & - & 13 & 48 \\
\hline Mumps* & 1 & - & - & 1 & - & - & - & - & - & - & 1 & - & - & - & - & - & - & 3 & 18 \\
\hline Pertussis & 3 & 6 & 6 & 2 & 4 & 3 & 3 & 14 & 10 & 3 & 21 & 2 & 1 & 2 & - & 2 & 3 & 85 & 1022 \\
\hline Rubella* & - & - & - & - & - & - & - & - & - & 1 & - & - & - & - & - & - & - & 1 & 14 \\
\hline Tetanus & - & - & - & - & - & - & - & - & - & - & - & - & - & - & - & - & - & - & 1 \\
\hline Faecal- oral & & & & & & & & & & & & & & & & & & & \\
\hline Botulism & - & - & - & - & - & - & - & - & - & - & - & - & - & - & - & - & - & - & - \\
\hline Cholera* & - & - & - & - & - & - & - & - & - & - & - & - & - & - & - & - & - & - & 1 \\
\hline Cryptosporidiosis & 4 & 2 & 6 & 9 & 10 & 12 & 6 & 2 & 9 & 11 & 5 & 3 & 1 & - & 1 & 1 & 6 & 88 & 963 \\
\hline Food-borne illness (not otherwise specified) & - & - & 1 & - & - & - & - & - & - & - & - & - & - & - & - & - & - & 1 & 9 \\
\hline Gastroenteritis (in institution) & - & - & 1 & - & - & - & - & - & - & - & - & - & - & - & 1 & - & - & 2 & 112 \\
\hline Haemolytic uraemic syndrome & - & - & - & - & - & - & - & - & - & - & - & - & - & - & - & - & - & - & 2 \\
\hline Hepatitis A & 4 & 6 & 6 & 4 & 1 & 2 & - & 6 & 15 & 18 & 2 & 1 & - & 5 & - & - & - & 70 & 499 \\
\hline Hepatitis E & - & - & - & - & - & - & - & - & - & - & - & - & - & - & - & - & - & - & 4 \\
\hline Listeriosis* & - & - & - & - & - & - & - & - & - & - & 1 & - & - & - & - & - & - & 1 & 16 \\
\hline Salmonellosis (not otherwise specified) ${ }^{\star}$ & 11 & 22 & - & - & - & 14 & 15 & 3 & - & 14 & 4 & 4 & 3 & 4 & 1 & 2 & 2 & 120 & 908 \\
\hline Typhoid and paratyphoid* & 1 & 1 & - & - & - & - & - & - & - & - & - & - & - & - & - & - & - & 2 & 15 \\
\hline Verotoxin-producing E. coli & - & - & - & - & - & - & - & - & - & - & - & - & - & - & - & - & - & - & 1 \\
\hline lab-confirmed cases only ${ }^{* *}$ includes cases & th unkr & vn pos & & & & & & & & & & & & & & & & & \\
\hline CSA = Central Sydney Area & entworth & Area & & & $\mathrm{V}=\mathrm{Hu}$ & Area & & & NR & $=$ Nort & n Riv & Area & & $C=M$ & quarie & ea & & $=$ Greater & Murray Area \\
\hline NSA $=$ Northern Sydney Area & uth Wes & ern Sydr & ey Area & & $=$ Illawar & a Area & & & & $=$ Nor & Coast $A_{r}$ & & & & Westerr & Area & & $=$ Southern & \\
\hline WSA = Western Sydney Area & ntral Cos & st Area & & SE & = Sout & Eastern & Sydney & Area & NEA & $=$ New $\mathrm{E}$ & gland $\mathrm{A}$ & & & $\mathrm{A}=\mathrm{Far}$ & Nest Are & & & & \\
\hline
\end{tabular}

